\title{
ABBREVIATIONS
}

The following abbreviations are used with the German words in this dictionary and are taken from Wahrig's Deutsches Wörterbuch. The grammatical information is placed five spaces after each German word and the stylistic and regional information is placed approximately eight spaces after each word. Words limited to a particular technical usage are relatively infrequent in this dictionary, and words restricted to regional usage are very rare.

The grammatical information is limited to part of speech and gender notation and is given in cases of ambiguity or in instances where the gender is not immediately clear from the suffix. Thus, for example, nouns ending in -UNG or -KEIT such as Achtung, Änlichkeit are not labeled NF, verbs ending in -EN such as arbeiten, tragen are not labeled V, and adjectives ending in - LICH such as ärgerlich, freundlich are not labeled A. It is suggested that the reader use this grammatical information together with the information contained in the list of suffixes.

Grammatical Information 

A adjective
AV adverb
P preposition
C conjunction

Stylistic Information
A archaic or obsolete
B business or trade
C chancery
G Brammatical term
$H$ hunting term
I rare
L legal
M military
$N$ nautical
O sport
P poetic
S lang
T technical or scientific

\section{Regional Usage}
AU Austrian
CH Swis:
LG lower German
NG north German
RH Rhine
UG upper German 